Ueber eine Nethode der Ausscheidung und quantitativen Bestim= mung des Digitalins, Digitaleïns und Digitins.

$$
\text { Von }
$$

\title{
R. Palm.
}

Von den Glykosiden ist kaum ein anderes so vielen Bearbeitungen unterworfen gewesen, um zuverlässige und bequeme Methoden der Gewinnung festzustellen, als das Digitalin. Sowohl das deutsche Verfahren zur Gewinnung desselben, als auch das prämiirte, französische $\mathrm{Nati-}$ velle'sche, später modificirt von Binguet, sind so umständlich, kost"spielig und zeitraubend, dass es wünschenswerth erschien, andere Methoden - besonders was Einfachheit der chemischen Operationen anbetrifft - ausfindig zu machen, was vorzugsweise bei Vergiftungsfällen mit Digitalis von bedeutendem Interesse wäre.

Das bisher bekannte deutsche Verfahren zur Ausscheidung des Digitalins aus der Digitalis purpurea beruht auf der Fällbarkeit desselben durch Gerbsäure; das französische dagegen gründet sich auf die Fällbarkeit des Digitalins und Digitins durch Wasser aus einem spirituösen Auszuge des Krautes, während das Digitaleïn bei diesem Processe als in Wasser leicht löslich in Lösung bleibt.

Das hier in Vorschlag zu bringende Verfahren zur Ausscheidung des Digitalins beruht auf der Fällbarkeit desselben durch Bleiessig und alkoholisches Ammon, welches Verhalten analog dem des Pikrotoxins ist.

Das allgemeine Verfahren zur Ausscheidung der Glykoside aus dem Kraute der Digitalis lässt sich in Kürze folgender Weise ausführen.

Das gröblich gepulverte Kraut wird mit Wasser erschöpfend ausgezogen, der Auszug über Thierkohle mehrere male bis zur vollständigen Entfärbung filtrirt, das Filtrat bis zur vollständigen Fällung mit einer Lösung von Bleiacetat versetzt. Die vom hierbei gebildeten Niederschlage abfiltrirte Flüssigkeit wird jetzt so lange mit einer Lösung von Bleiessig und alkoholischem Ammon (12 Theile Bleiessig und 1 Theil Liquor Dzondii) versetzt, als hierbei noch ein Niederschlag 'erzeugt wird. Dieser letztere Niederschlag besteht nun aus Bleioxyd und den Glykosiden der Digitalis. Derselbe wird nach dem Auswaschen auf einem Filter mit Wasser zum dünnen Brei angerührt und letzterer durch Hineinleiten von Schwefelwasserstoffgas vollständig zersetzt. Der ganze Brei, bestehend aus Bleisulfid und den frei gewordenen Glykosiden wird jetzt auf ein Filter gebracht. Die hierbei abfiltrirende 
wässerige Flüssigkeit enthält alles Digitaleïn, während Digitalin und Digitin als in Wasser schwer lôsliche Substanzen mit dem Bleisulfide ungelöst zurückbleiben. Behandelt man nun weiter den Bleirückstand mit Chloroform, so wird das Digitalin gelöst, aus welcher Lösung es durch Verdunsten des Chloroforms krystallisirt erhalten werden kann, und beim endlichen Behandeln des Bleisulfides mit Alkohol wird das Digitin gelöst, welches durch Verdunsten des Alkohols vollständjg rein zurückbleibt.

Dieses Verhalten des Digitalins gegen Bleiessig und alkoholisches Ammon ist besonders zur Ausscheidung desselben in Vergiftungsfällen empfehlenswerth, indem durch 'diese Reaction auch Spuren des Giftes angezeigt, werden, da eine vollständige Fällung desselben stattfindet. Bei der fabrikmässigen Darstellung des Digitalins ans dem Kraute nach angeführter Methode ist noch der Umstand besonders̀ hervorzuheben, dass nach dem Behandeln des wässerigen Auszuges mit Bleiacetat behufs Fällung von Schleim, Proteïn, Farbstoffen u. s. w. es nicht erforderlich ist überschüssig zugefügtes Bleisalz zu entfernen, indem hierbei zur weiteren Fällung des Digitalinś Bleiessig und alkoholisches Ammon zugefügt werden muss.

Wie schon angeführt, wird auch das Pikrotoxin unter denselben Umständen gefällt, welches Verhalten bei gerichtlich-chemischen Untersuchungen Veranlassung zu Täuschungen geben könnte; ebenso wird auch von anderen giftig wirkenden Glykosiden das Solanin gefällt, welches letztere indessen auch schon durch Bleiessig allein ohne Zusatz von alkoholischem Ammon niederfällt.

Ausserdem lassen sich die Bleiniederschläge dieser drei giftig wirkenden Glykoside in Vergiftungsfallen durch folgende Reactionen sogleich von einander unterscheiden.

1) Der Bleiniederschlag des Pikrotoxins ist mehr schleimig und wird durch Zusatz von concentrirter Schwefelsäure safrangelb.

2) Der Bleiniederschlag des Digitalins ist gelatinös, wird durch concentrirte Schwefelsäure fleischfarbìg bis hell-rehfarben.

3) Der Bleiniederschlag des Solanins ist sandig, wird durch concentrirte Schwefelsäure dunkel-rehfarben. Fügt man dann zum Gemische etwas Zucker, so ninmt dasselbe nach einiger Zeit.erst eine violette, später blau werdende Färbung an. 